\title{
Numerical Prediction of a Surge Vortex during Winter Monsoon
}

\author{
By Ming-Cher Tsai and T. N. Krishnamurti \\ Department of Meteorology, Florida State University, Tallahassee, Florida 32306, U.S.A. \\ (Manuscript received 12 February 1986, in revised form 27 May 1986)
}

\begin{abstract}
This paper presents the results of several global experiments that were carried out to study the formation of a surge vortex. This vortex formed over the South China Sea during the Winter Monsoon season. The numerical experiments explore the sensitivity of the prediction to horizontal and vertical resolution, to the use of high resolution cloud winds, and to two different representations of orography. The results of these studies show that the simulation of the surge vortex was only possible at a minimal horizontal resolution of 42 waves (triangular), 11 vertical levels and the use of envelope orography. The results did not appear to be sensitive to the inclusion of high resolution cloud winds. A major synoptic aspect of this study deals with the interaction of westward propagating easterly waves and the quasi-stationary cold surge over the South China Sea. That aspect of the cyclogenesis was shown observationally as well as via the numerical weather prediction experiment. That interaction appears to be quite sensitve to the inclusion of steep orography.
\end{abstract}

\section{Introduction}

The scenario of a cold surge from east Asia towards the South China Sea usually is initiated from a build-up of the Siberian High. The intense build-up of this High is related to the strong radiative cooling of the surface air. Around this anticyclone, especially to its southeasterly flank, a stationary cold front is usually present. Cyclogenesis along this front, over east Asia and Japan, is usually triggred by the passage of upper level systems. As these cyclones move eastward, and northeastwards, the anticyclone to its rear (or to its west) usually moves southeastwards with an accompanied built-up of pressure gradient along the east coast of China.

The occurrence of these cold surges is associated with a build-up of the meridional pressure gradient over China extending into the South China Sea. A measure of this pressure gradient is a so-called Hong Kong index. This is measured by the pressure difference between a point located due north of Hong Kong around $30^{\circ} \mathrm{N}$ and Hong Kong. Fig. 1 denotes a time sequence of this pressure differential during the Winter Monsoon period, i.e. December 1978. During this month there were 5 major cold surge events over the South China Sea. The onset dates of these cold surges asre denoted by small arrows in Fig. 1. It is apparent that the pressure gradient built up subsequent to the onset date.

After a careful inspection of surface winds we have noted that the surface northerly wind attains a magnitude of around $10 \mathrm{~ms}^{-1}$ or larger during these surge events near $15^{\circ} \mathrm{N}$.

A rapid southward extension of the northerly winds has been ascribed as a gravitational impulse by Chang et al. (1979) and Lim and Chang (1981). An interesting phenomenon of regional interest is the westward propagation of easterly waves. They seem to propagate from the Pacific Ocean on to the South China Sea. Chang (1977), Greenfield and Krishnamurti (1979) and several others have provided observational evidence for these waves. The observations from the Winter Monsoon Experiment also provide evidence for an interaction of the northerlies (associated with the cold surge) and the westward propagating easterly waves. A consequence of this interaction appears to be the formation of a surge vortex over the South China Sea. This will be the 


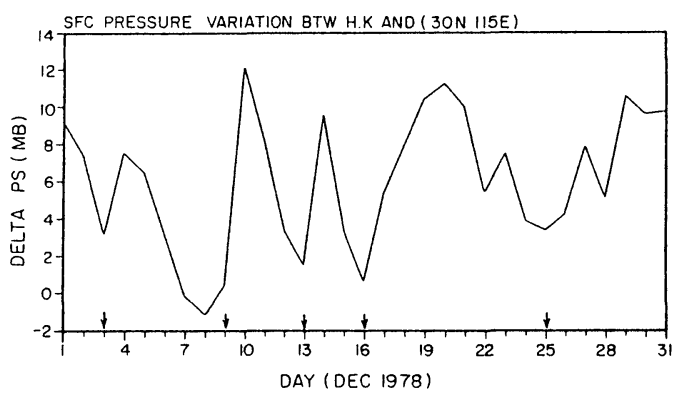

Fig. 1 This illustration shows the time evolution of the Hong Kong Index during December 1978. The Hong Kong Index is a pressure differential between a point at $30^{\circ} \mathrm{N}$ (due north of Hong Kong) and Hong Kong. Units: mb. The vertical arrows along the abscissa denote dates of major cold surges.

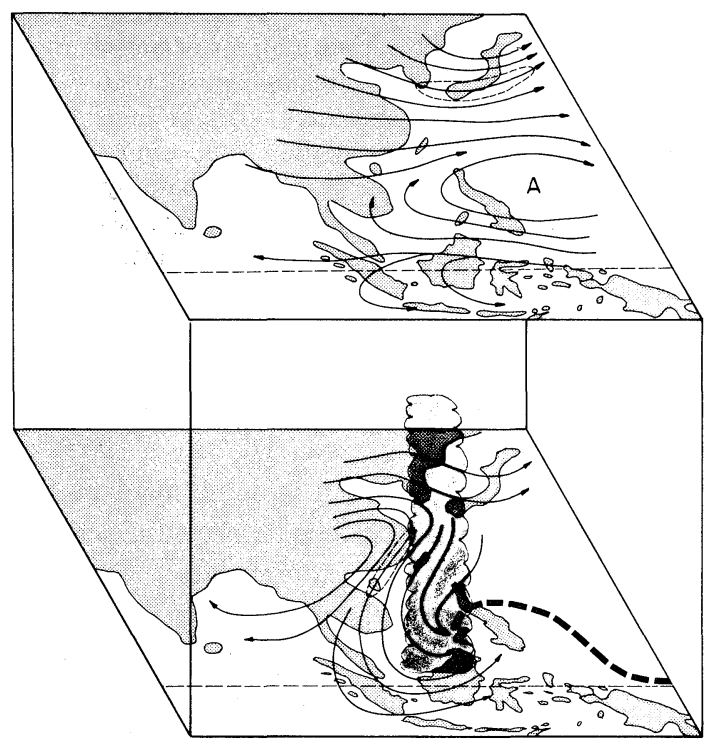

Fig. 2 A schematic diagram of the typical flow patterns at $200 \mathrm{mb}$ (top) and the $850 \mathrm{mb}$ (bottom). The heavy dashed line at bottom is a typical easterly wave which interacts with the northerly cold surge.

central topic of the present study. A schematic illustration of this interaction, based on winter monsoon observations, is shown in Fig. 2. In the lower panel of this illustration we show the easterly wave by a dark dashed line while the thin lines over the South China Sea depicts the northerly cold surge. The upper panel shows the western Pacific anticyclone A at $200 \mathrm{mb}$ and the subtropical westerly jet stream of winter to its north. The interaction between the easterly wave and the cold surge is usually accompanied by enhanced convection, intensification of the local Hadley circulation, the upper anticyclone and the subtropical jet stream of the winter season. This interaction of the easterly waves and the quasi-stationary northerly surges is an important scientific problem. In order to understand this phenomenon better one perhaps needs to cast the scale interaction problem in a wave number domain. We believe that both barotropic and baroclinic processes are important. Such an observational study is well worth examining. It is, however, beyond the scope of the present study.

\section{Objectives of Present Study}

The main objective of this study is to carry out a numerical prediction of the surge vortex over the South China Sea.

The data sets from the Special Observing Period of FGGE (The First GARP Global Experiment) and of the Winter Monsoon Experiment, WMONEX, appeared to be best suited for such a study. Prediction over this region is quite sensitive to data sets, orographic processes, resolution of the model and physical processes. The present study is aimed at examining the sensitivity of the forecast to some of these factors. Table 1 provides a list of experiments that were carried out for this study.

\section{Observational Aspects of the Initial State}

The flow field at $850 \mathrm{mb}$ for December 10 , 11, 12, 13 and 14, 1978 (00GMT) clearly portrays the formation of a surge vortex over the South China Sea (Figs. 3a, b, c, d and e). We have selected December 10, 1978 (00GMT) as the initial date for the prediction experiment. At this time the trade winds at $850 \mathrm{mb}$ were extending into the East China Sea. Northerly flow over east China had a maximum value of around $11.7 \mathrm{~ms}^{-1}$. A weak easterly wave is present over the western Pacific Ocean near $140^{\circ} \mathrm{E}$ and $5^{\circ} \mathrm{N}$. This is a region of strong cyclonic shear since this weak wave is located on the equatorward side of a wind maximum (16.4 $\mathrm{ms}^{-1}$ ) in the trade wind belt. Most of the other features of the flow at $850 \mathrm{mb}$ are essentially the climatological features of the Northern Winter season. In the subsequent four days (see Figs. 3b, c, d and e) a vortex forms over the 
Table 1 A list of experiments

\begin{tabular}{|c|c|c|c|c|c|c|c|c|}
\hline \multirow[t]{2}{*}{$\begin{array}{l}\text { Experi- } \\
\text { ment }\end{array}$} & \multicolumn{2}{|c|}{ Orography } & \multicolumn{2}{|c|}{ Horizontal resolution } & \multicolumn{2}{|c|}{ Vertical resolution } & \multicolumn{2}{|c|}{$\begin{array}{l}\text { High resolution } \\
\text { cloud winds }\end{array}$} \\
\hline & Normal & Envelope & R-29 & $\mathrm{T} 42$ & 5 & 11 & Yes & No \\
\hline 1 & $\mathrm{X}$ & & $\mathrm{X}$ & & $\mathrm{X}$ & & & $\mathrm{X}$ \\
\hline 2 & $\mathrm{X}$ & & $\mathrm{X}$ & & $\mathrm{X}$ & & $\mathrm{X}$ & \\
\hline 3 & $X$ & & $\mathrm{X}$ & & & $\mathrm{X}$ & $X$ & \\
\hline 4 & $\mathrm{X}$ & & & $\mathrm{x}$ & & $\mathrm{X}$ & $\mathrm{X}$ & \\
\hline 5 & & $\mathrm{X}$ & & $\mathrm{X}$ & & $\mathrm{X}$ & $\mathrm{X}$ & \\
\hline
\end{tabular}
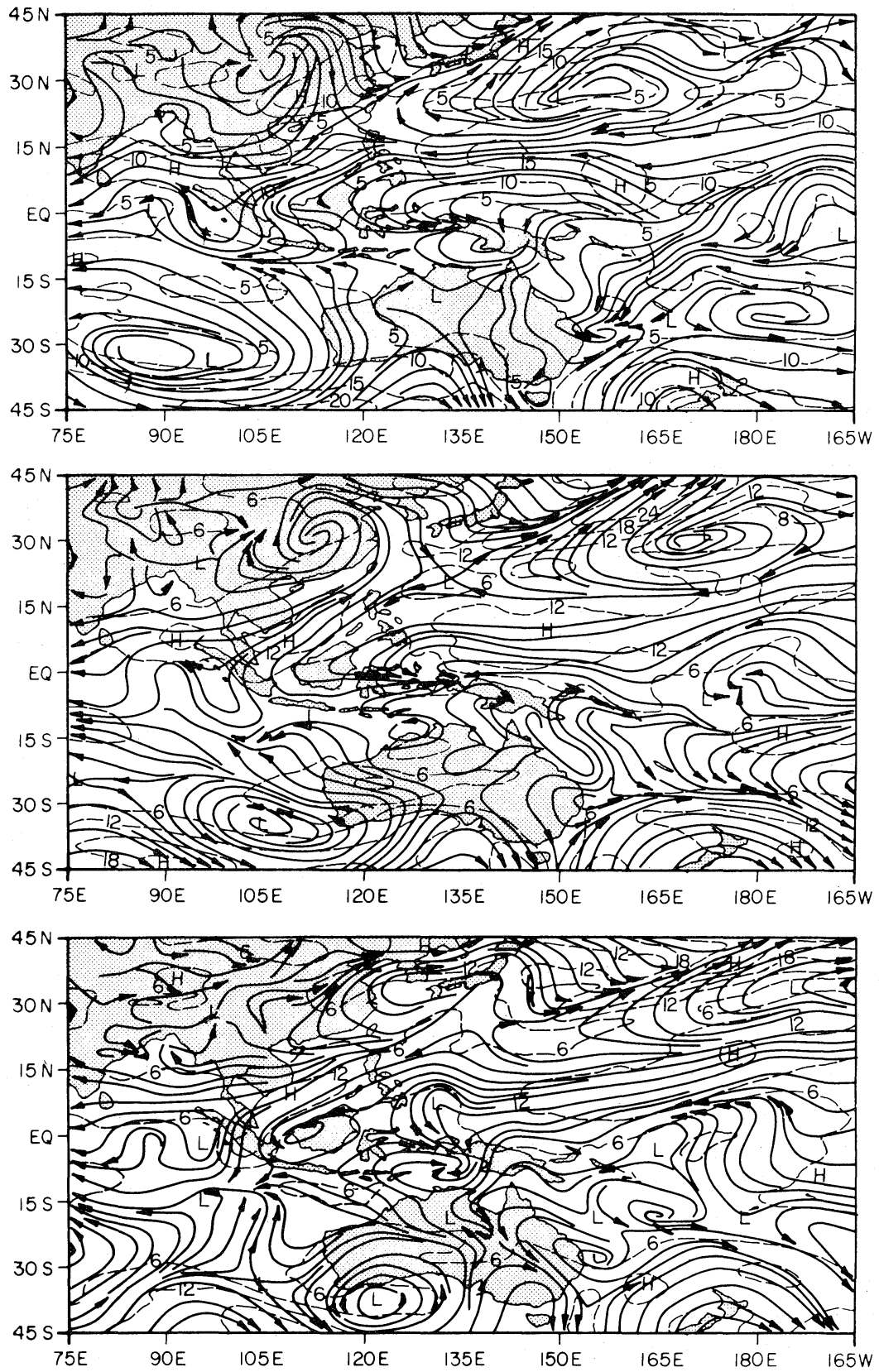

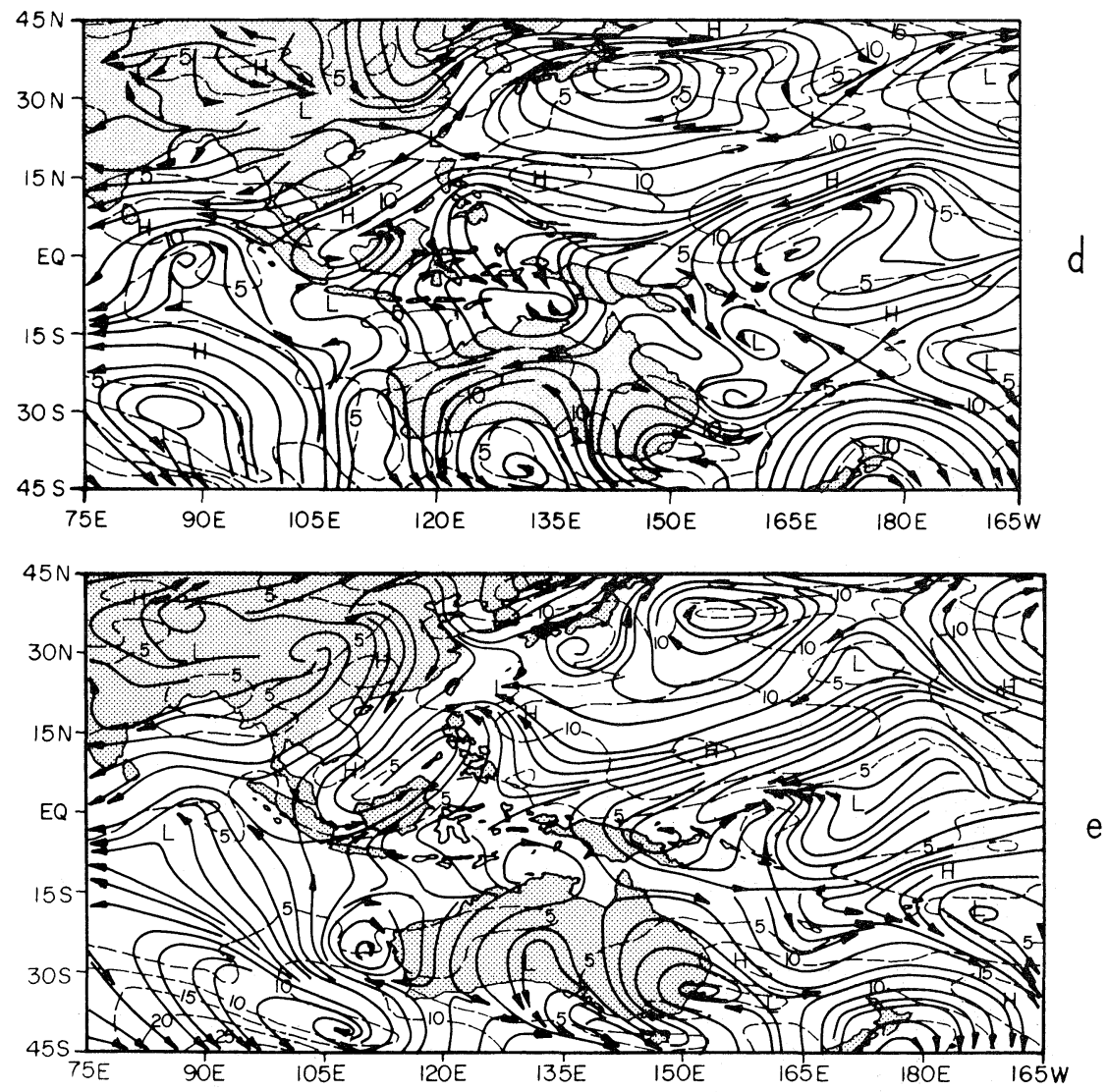

Fig. 3(a, b, c, d and e) Flow field at the $850 \mathrm{mb}$ surface for December 10, 11, 12, 13 and 14 respectively at $12 \mathrm{GMT}$. The solid lines are streamlines and the dashed lines are isotachs $\left(\mathrm{ms}^{-1}\right)$. These are based on FGGE/MONEX observations.

South China Sea. The $850 \mathrm{mb}$ flows on December 14 show an elongated vortex extending southwest to northeast over this region. The velocity maximum of the trade wind moves westward with this wave. The cold surge is manifested by northerly flows over the South China Sea which have an intensity of 12 to 13 $\mathrm{ms}^{-1}$ at the time of the formation of the vortex. It is also clear from these illustrations that these northerly flows have remained fairly strong through this 4 day period. The strongest value of the northerly flows was noted just prior to the formation of the vortex. The trade winds also exhibited their strongest intensity around this time.

The most succinct observational depiction of the interaction of the tropical wave and the quasi-stationary monsoon surge is provided by an $x$-t diagram, Fig. 4. Here we illustrate the relevant zonal harmonics (sum of the zonal harmonics 7 through 15) of the meridional wind at $5^{\circ} \mathrm{N}$ for the $850 \mathrm{mb}$ level. These components of the zonal harmonics carry most of the variance (almost $80 \%$ ) for the meridional wind at $850 \mathrm{mb}$ at this latitude. We have shown an entire month of data here although of interest to the present study is the period from December 10 to December 14, 1978. Here we note a quasistationary northerly wind component around $105^{\circ} \mathrm{E}$ longitude with considerable amplitude modulations. These are associated with the cold surge events shown in Fig. 1. A major build-up of northerlies around $105^{\circ} \mathrm{E}$ precedes the formation of the surge vortex immediately to the east of this longitude. Also noteworthy are the slanted lines of the meridional velocity that clearly suggest westward propagating easterly waves which were confirmed from a daily synop- 


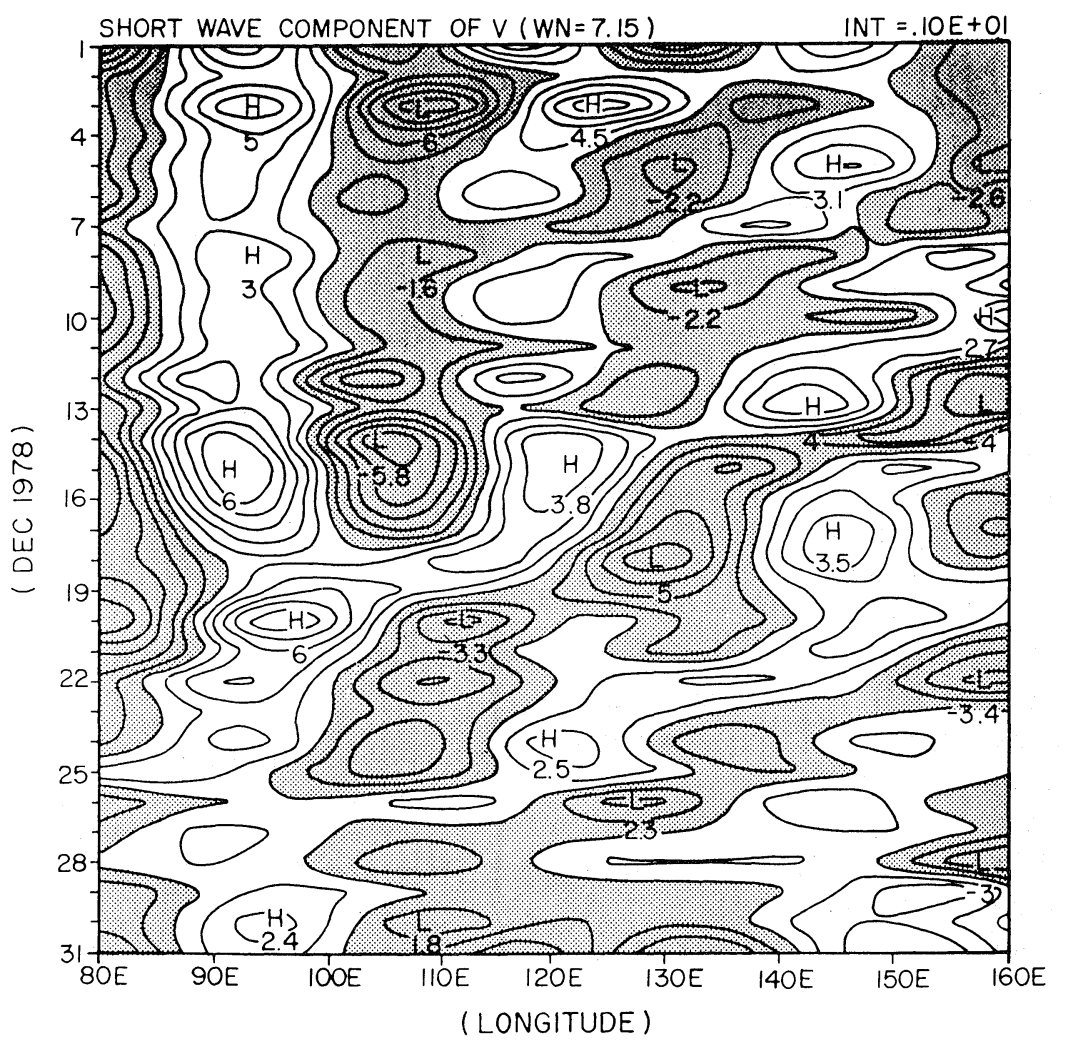

Fig. 4 A Hovmoller ( $\mathrm{x}-\mathrm{t}$ ) diagram of the meridional wind at $850 \mathrm{mb}$ for the short wave components (zonal harmonics 7 through 15). The abscissa shows the longitude around the globe, the ordinate shows dates during December 1978. Shaded area denotes northerly flow. Units: $\mathrm{ms}^{-1}$, latitude $5^{\circ} \mathrm{N}$.

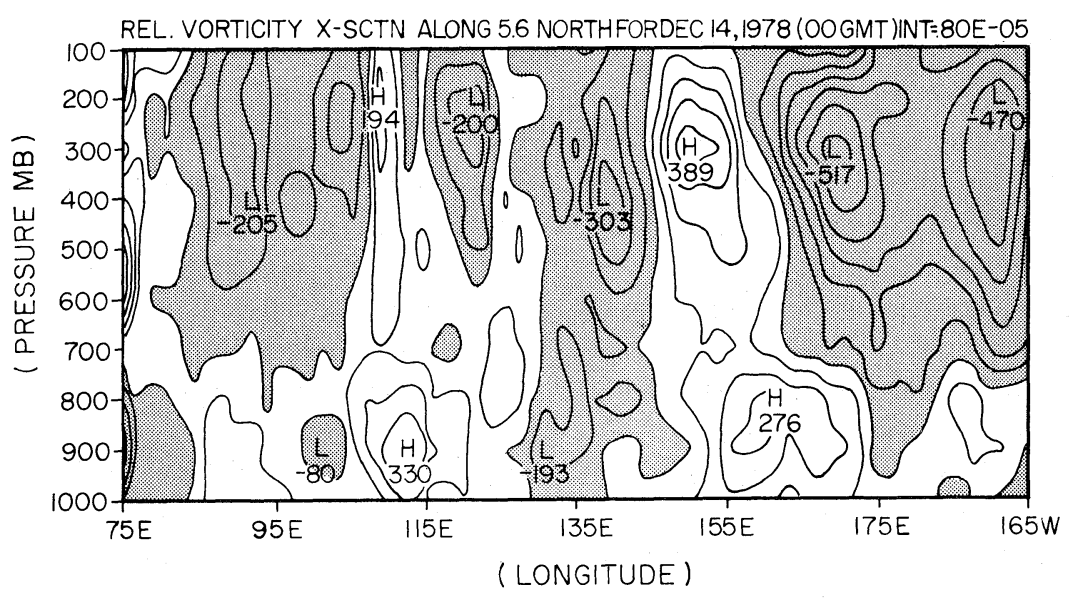

Fig. 5 Zonal cross-section of relative vorticity based on analyzed (observed) fields for December 14, 1978 00GMT. Interval of analysis $80 \times 10^{-5} \mathrm{sec}^{-1}$. Shaded area negative values. 
tic analysis over the western Pacific Ocean. The wavelength of these waves is around $3000 \mathrm{~km}$, and their speed of westward propagation is around 7.0 degrees longitude $\cdot \mathrm{day}^{-1}$. It is also quite clear in this illustration that a major westward propagating easterly wave arrives over the South China Sea around December 14 as the surge vortex develops.

Also of some interest in this illustration are the southerly surges around $90^{\circ} \mathrm{E}$ over the southern Bay of Bengal. This feature has not been described previously. A zonal cross section of the relative vorticity field is shown in Fig. 5. Here the cross-section is taken across the center of the storms circulation for December 14, 1978 (00GMT) based on observations. A vorticity maxima (about $330 \times 10^{-6} \mathrm{sec}^{-1}$ ) near $112^{\circ} \mathrm{E}$ denotes the surge vortex. This maximum value is located close to $900 \mathrm{mb}$, at which level the strongest northerly flows were also found.

Johnson and Preignitz (1981) have examined the convection over this region. They noted a strong diurnal modulation of convection in the vicinity of North Borneo. From the Soviet ship observations, in the vicinity of $5^{\circ} \mathrm{N}$ over South China Sea, they have made estimates of the vertical distribution of the vertical motion, divergence and humidity. Their studies do reveal the westward passage of disturbances over their regions.

\section{Brief Description of Prediction Model}

The forecast model utilized in the present study is the same as that described in Krishnamurti et al. (1983a, 1984). The following is an outline of the major ingredients of this forecast model. 5 or 11 vertical levels were deployed in the various experiments. The experiments were run on two different horizontal resolutions: 29 waves (Rhomboidal) and 42 waves (Triangular). Semiimplicit time differencing and the spectral transform method describes the basic computational design of the model. Modified Kuo's scheme based on Krishnamurti et al. (1983b) describes the cumulus parameterization. Other aspects of the model include shallow convection based on Tiedke (1984), dry convective adjustment, surface fluxes based on similarity theory, planetary boundary layer fluxes distributed following mixing length theory, large scale condensation,

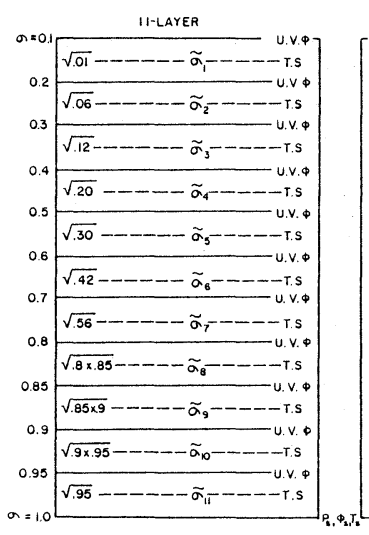

a

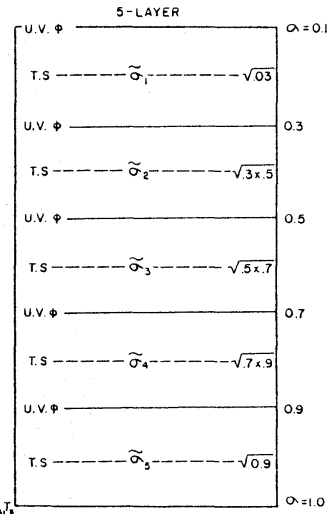

b
Fig. 6(a, b) The two panels respctively denote the vertical dexterization for the 11 and the 5 level models. The symbols are described in Krishnamurti et al. (1984). The velocity components $\mathrm{u}, \mathrm{v}$ and the geopotential appear at the sigma levels while the temperature $\mathrm{T}$ and the humidity variable $S$ appear at the intermediate (sigma tilda) levels.

radiative processes including diurnal change and cloud feedback processes. For the representation of orography we have utilized a smoothed $\bar{h}$ as well as an envelope orography $(\bar{h}+2 \sigma)$ (following Wallace et al., 1984). Here 2 denotes twice the standard deviation of a high resolution orography. Fig. $6(\mathrm{a}, \mathrm{b})$ illustrates the vertical discretization of variables for the 11 and the 5 layer models. The dashed lines denote the socalled sigma tilda levels where the value is given by $\tilde{\sigma}=\sqrt{\sigma_{\mathrm{n}} \sigma_{\mathrm{n}+1}}$. The envelope orography is illustrated in Fig. 8. The highest mountains over Borneo, New Guinea and Sumatra range between 1.5 to $3 \mathrm{~km}$. The surge vortex appears to be well confined between the mountains over Indochina (to the north), Sumatra (to the southwest), Borneo (to the east) and the Phillipines (to the northeast).

\section{Results on Numerical Experimentation}

A large number of global prediction experiments were conducted to explore, a) the effects of satellite derived high resolution cloud winds, b) horizontal resolution, c) vertical resolution and d) two representations of orography.

The high resolution cloud winds were introduced at the 850 and the $200 \mathrm{mb}$ levels. The first guess for the global analysis was obtained 

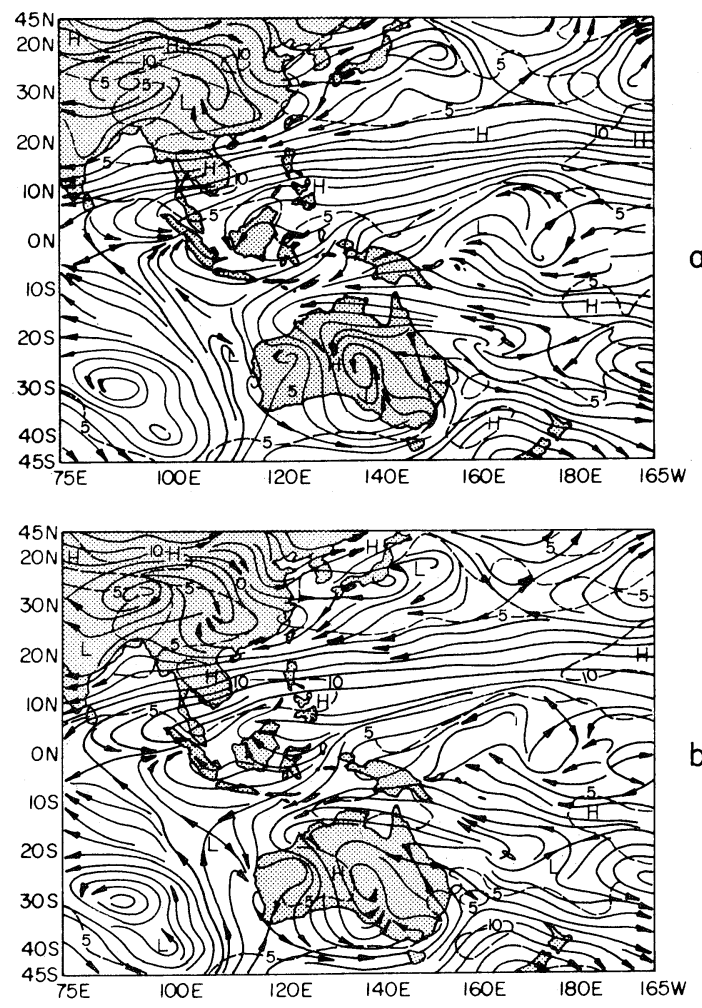

Fig. 7(a, b) These two illustrations show the $850 \mathrm{mb}$ circulation forecasts on day 4 valid on December 14, 1978 ODGMT. The top panel shows a forecast made without use of high resolution cloud winds, while the bottom panel is a 4 day forecast using high resolution cloud winds. The solid lines are streamlines, dashed lines are isotachs $\left(\mathrm{ms}^{-1}\right)$.

from the FGGE IIIb data analyzed by the ECMWF. The high resolution cloud winds at low and high levels were analyzed at 850 and $200 \mathrm{mb}$ as additional data. The difference in analysis was assumed to be linearly distributed along the vertical for the first guess and the final analysis. Experiments at the 5 and 11 vertical levels at 29 and 42 wave horizontal resolutions did not seem to show much of an impact when these additional data were inserted. The lack of any substantial impact was noted from several experiments utilizing the 5 as well as an 11 level global model. The results of two four day forecasts made with and without the inclusion of high resolution cloud winds are shown in Fig. $7(a, b)$. These are circulation features at 850 $\mathrm{mb}$ for December 14, 1978, 00GMT. The

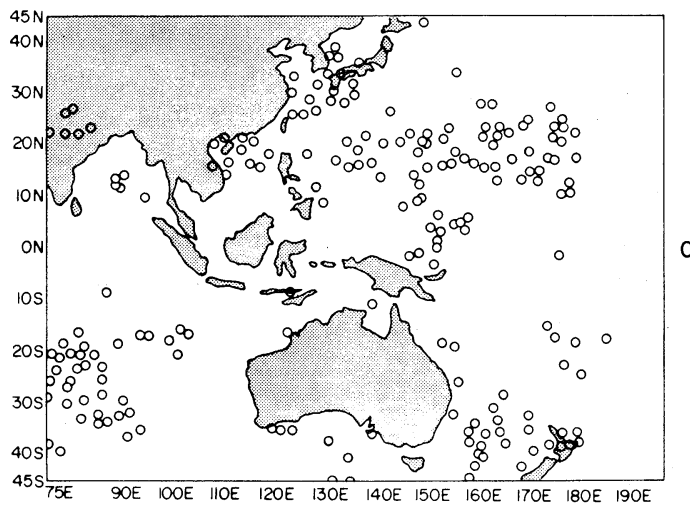

Fig. 7(c) The location of low level cloud motion vectors within the FGGE IIb data set are shown here.

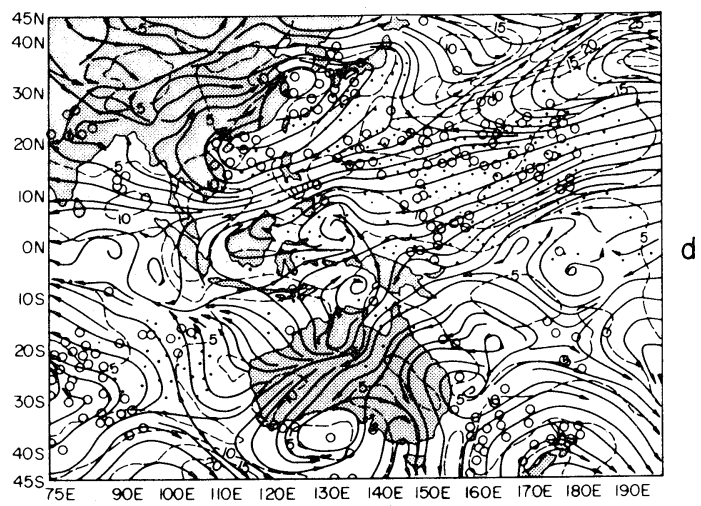

Fig. 7(d) The location of the enhanced data base of the low level cloud motion vectors obtained from the University of Wisconsin are shown here.

verification (or the observed flow field) was shown in Fig. 3e. It is apparent that both of these forecasts fail to simulate the surge vortex. Furthermore the forecasts shown in Fig. 7(a,b) strongly resemble each other, suggesting almost no impact from the inclusion of high resolution cloud winds. We ran several experiments starting from December 11, 12, 13 and 14 and noted similar results. This lack of sensitivity to cloud winds is due to the absence of sufficient low cloud motion vectors in the disturbed area. For the most part we noted a plethora of low cloud motion vectors over the undisturbed trades, which were already described reasonably well by the first guess field, i.e. the FGGE IIIb analysis. Figs. 7c and d show the data distribution from the FGGE IIb files and the high resolu- 
tion low cloud motion vector files. Most of the additional winds are over the undisturbed trades.

The impact of horizontal as well as vertical resolution was addressed by carrying out a series of experiments on 29 versus 42 wave resolution, at 5 and 11 vertical levels each. None of these experiments was successful in simulating the formation of the surge vortex over the South

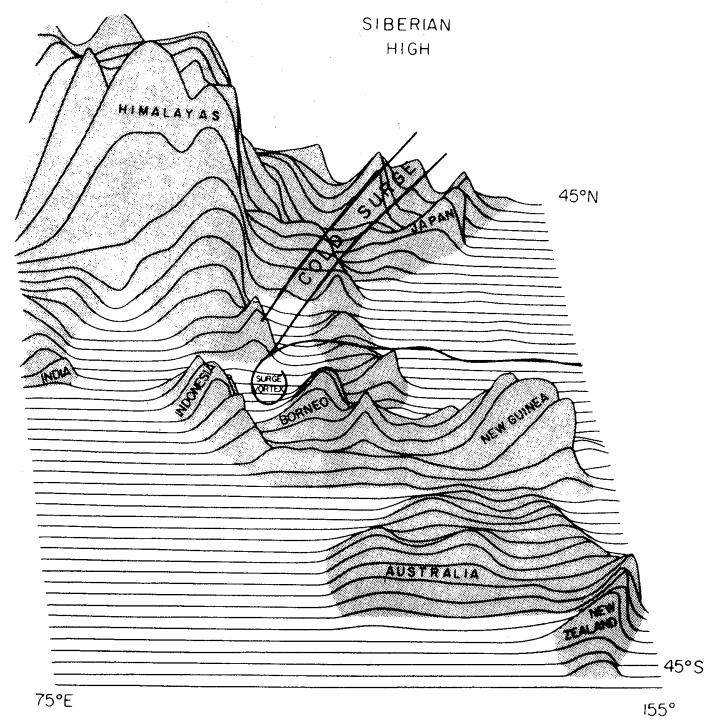

Fig. 8 This diagram illustrates the envelope orography over the winter monsoon region. Units: meters. A schematic flow pattern of the surge vortex at $850 \mathrm{mb}$ is shown here. The flows are confined by the tall mountains of the envelope orography over the South China Sea.
China Sea. A series of experiments was also carried out with the two representations of orography at the different horizontal and vertical resolutions. The most successful results on the simulation of the surge vortex were obtained when envelope orography Fig. 8, was used at a resolution of 42 waves (triangular) and 11 vertical levels. Fig. 9(a, b and c) respectively illustrate the 96 hour prediction of the motion field at $850 \mathrm{mb}$ for the following parameters:

a) Vertical resolution 5 levels, horizontal resolution 29 waves and normal orography.

b) Vertical resolution 11 levels, horizontal resolution 42 waves and normal orography.

c) Vertical resolution 11 levels, horizontal resolution 42 waves and envelope orography.

From these and other comparisons it appears that the steep orography (at a resolution of 42 waves) is an important factor in the cyclogenesis over the South China Sea. The northerly flow is confined as a sharp current by the mountains of southern Indochina, Malaysia, Indonesia and Borneo. This was apparent in Fig. 7, where we have schematically projected the northerly surge and a surge vortex. The mountains of the envelope orography are about a $\mathrm{km}$ higher than the normal orography over this region (see Krishnamurti et al., 1984). The arrival of the westward propagating wave into the region of the South China Sea enables the confined northerly flows to interact and form the surge vortex. This is apparent from Fig. 10, where we show an $x-t$ diagram of the predicted meridional flow along

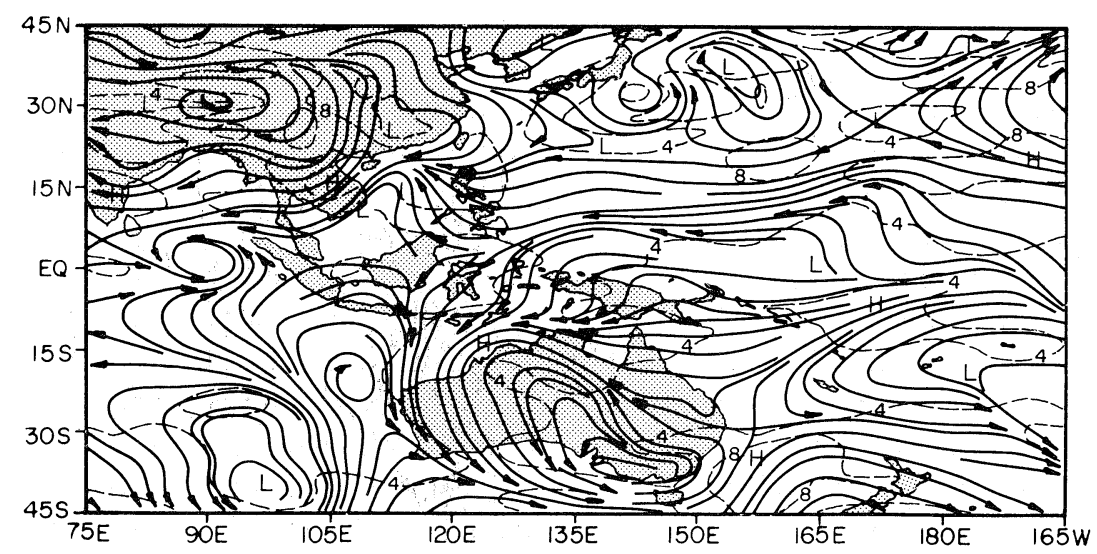

Fig. 9(a) 4 day forecast of the circulations at $850 \mathrm{mb}$ made with a 5 level, 29 wave normal orography model. Solid lines streamlines, dashed lines isotachs $\mathrm{ms}^{-1}$. Forecast valid on December 14, 1978 00GMT. 


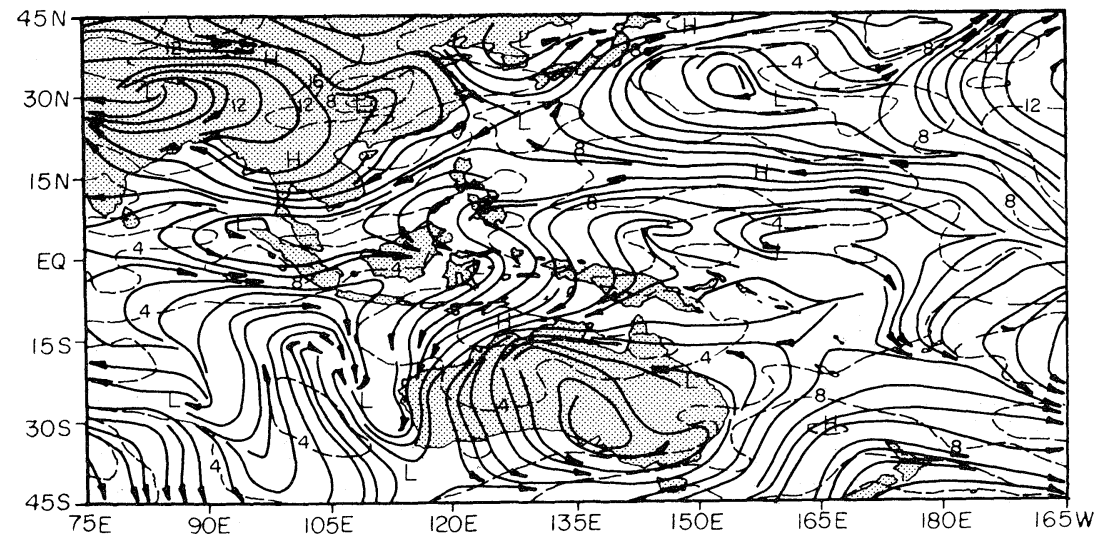

Fig. 9(b) 4 day forecast of the circulations at $850 \mathrm{mb}$ made with an 11 level 42 wave model utilizing normal orography solid lines streamlines dashed lines isotachs $\mathrm{ms}^{-1}$. Forecast valid on December 14, 1978 00GMT.

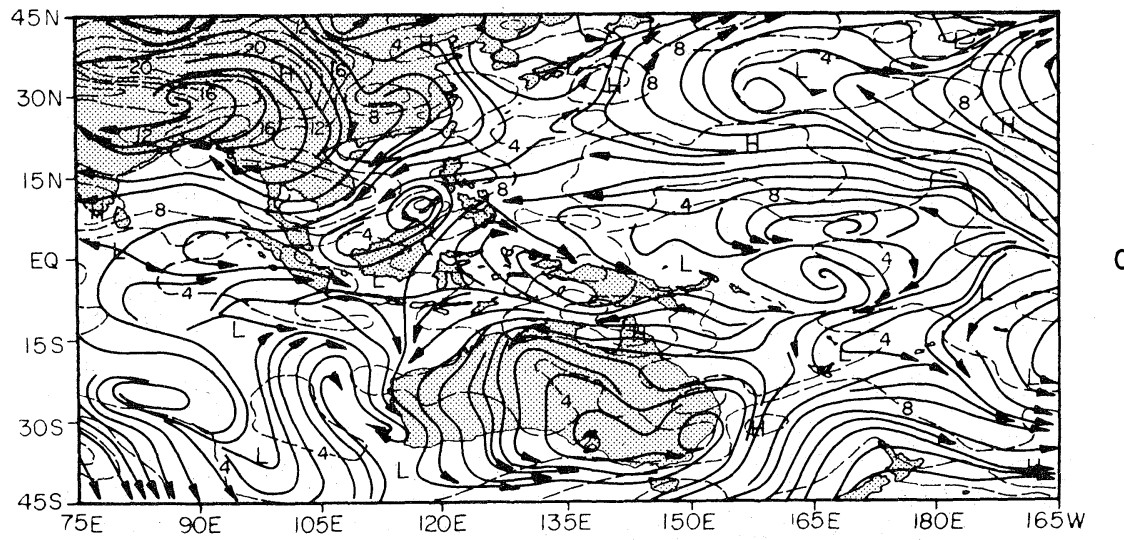

Fig. 9(c) 4 day forecast of the circulation at $850 \mathrm{mb}$ made with a 11 level, 42 wave envelope orography model. Solid lines streamlines, dashed lines isotachs $\mathrm{ms}^{-1}$ Forecast valid on December 14, 1978 00GMT.

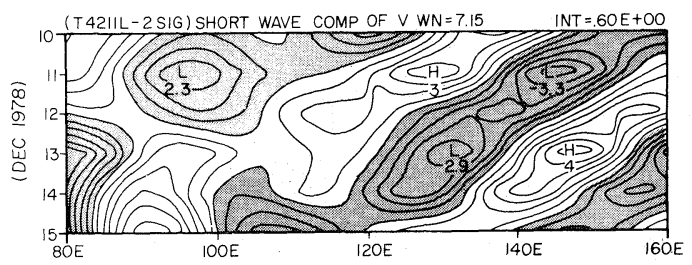

Fig. 10 Predicted $x-t$ Hovmoller diagram of the meridional wind, zonal harmonics 7 through 15 are included here. Shaded area northerly flow. The units $\mathrm{ms}^{-1}$. Results of 5 day forecast along $5^{\circ} \mathrm{N}$ at $850 \mathrm{mb}$ over Winter Monsoon region is shown here.

$5^{\circ} \mathrm{N}$ at $850 \mathrm{mb}$. A comparison of this diagram with that based on observations (Fig. 4) shows a close similarity. This suggests strongly the hypothesis of an interaction of westward propa- gating waves and the confined northerly flows over the South China Sea. The envelope orography appears to contribute to the lack of movement of the northerly flow during the formation of the surge vortex.

Another relevant calculation of this forecast is the structure of the vorticity field on day 4 . This is shown in Fig. 11. This predicted zonal cross-section of the relative vorticity may be compared with the counterpart based on observation (Fig. 5). The predicted and the observed vorticity exhibit a reasonable agreement by day 4 over the South China Sea where the storm formed. It is worth noting that no such correspondence of the predicted vorticity was found in the absence of envelope orography and lower 


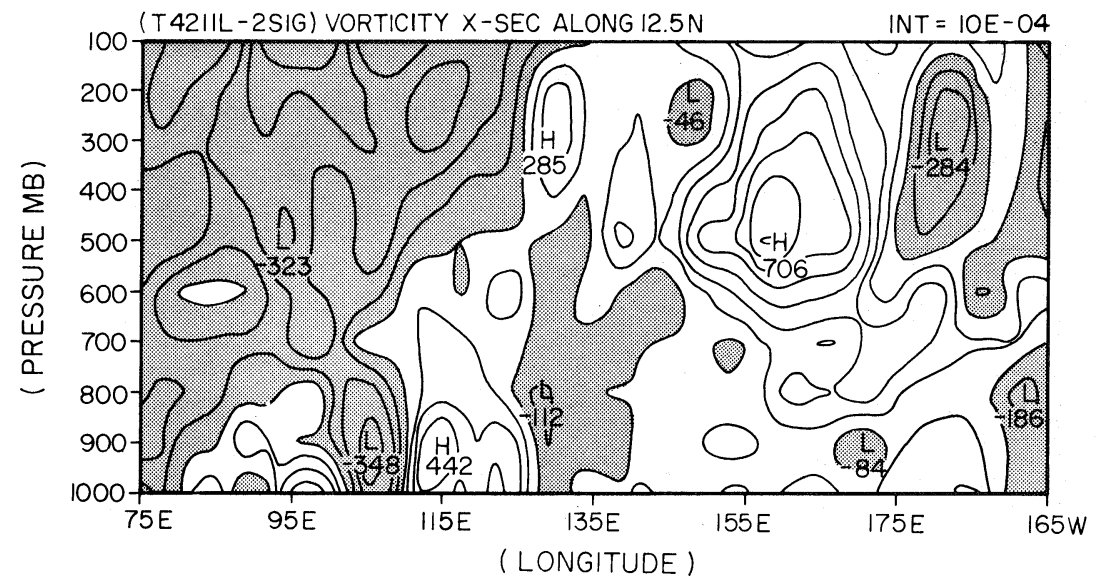

Fig. 11 Zonal cross-section of relative vorticity on day 4 of prediction. Valid on December 14,1978 OOGMT along $12.5^{\circ} \mathrm{N}$. Interval of analysis $10^{-5}$ $\sec ^{-1}$. Shaded area denotes negative values.
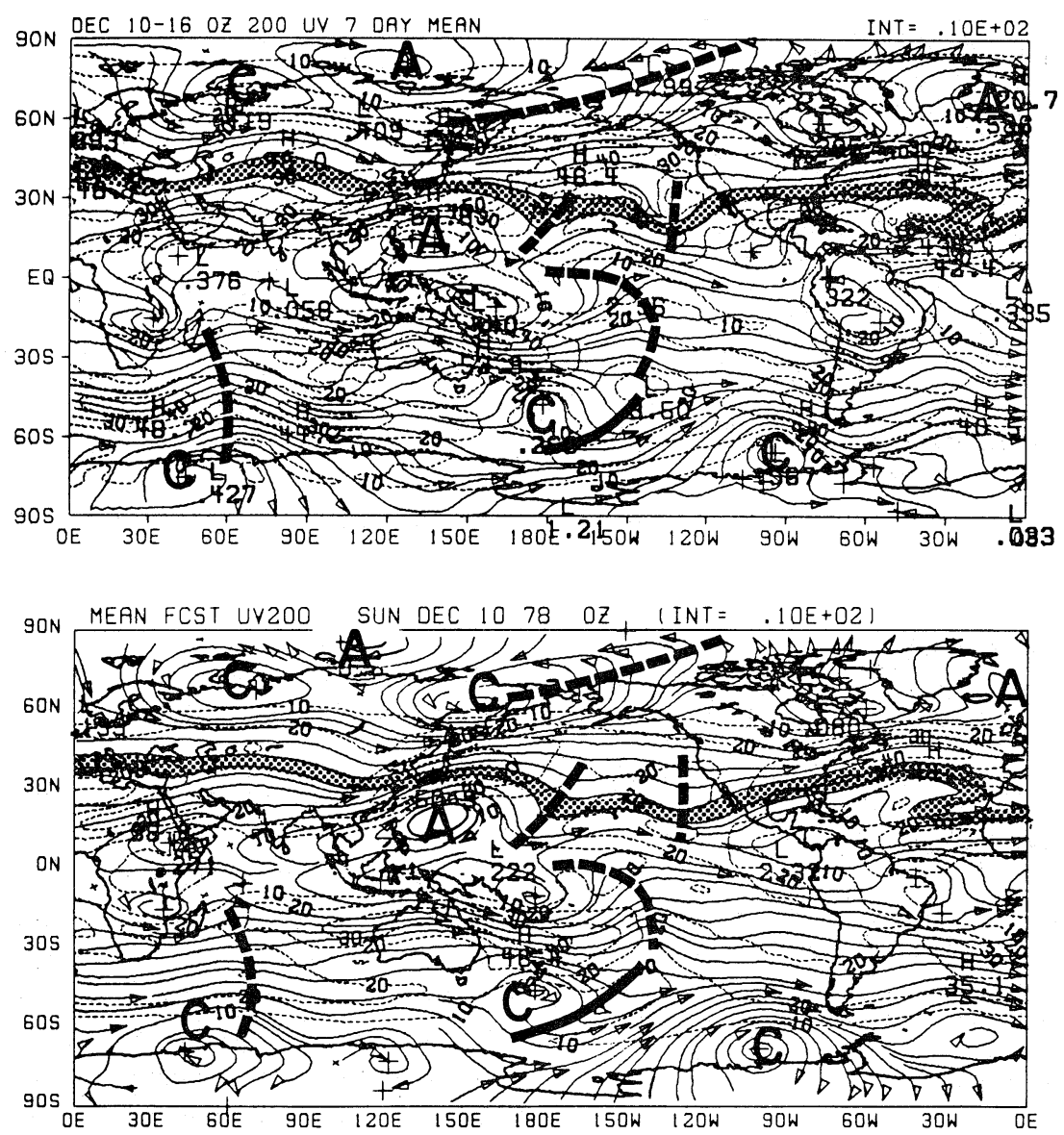

Fig. 12(a, b) Observed and predicted 7 day averaged flow pattern at $200 \mathrm{mb}$ from December 10 to December 17, 1978 (OOGMT). Solid lines streamlines, dashed lines isotachs $\mathrm{ms}^{-1}$. Interesting matching features are emphasized. 


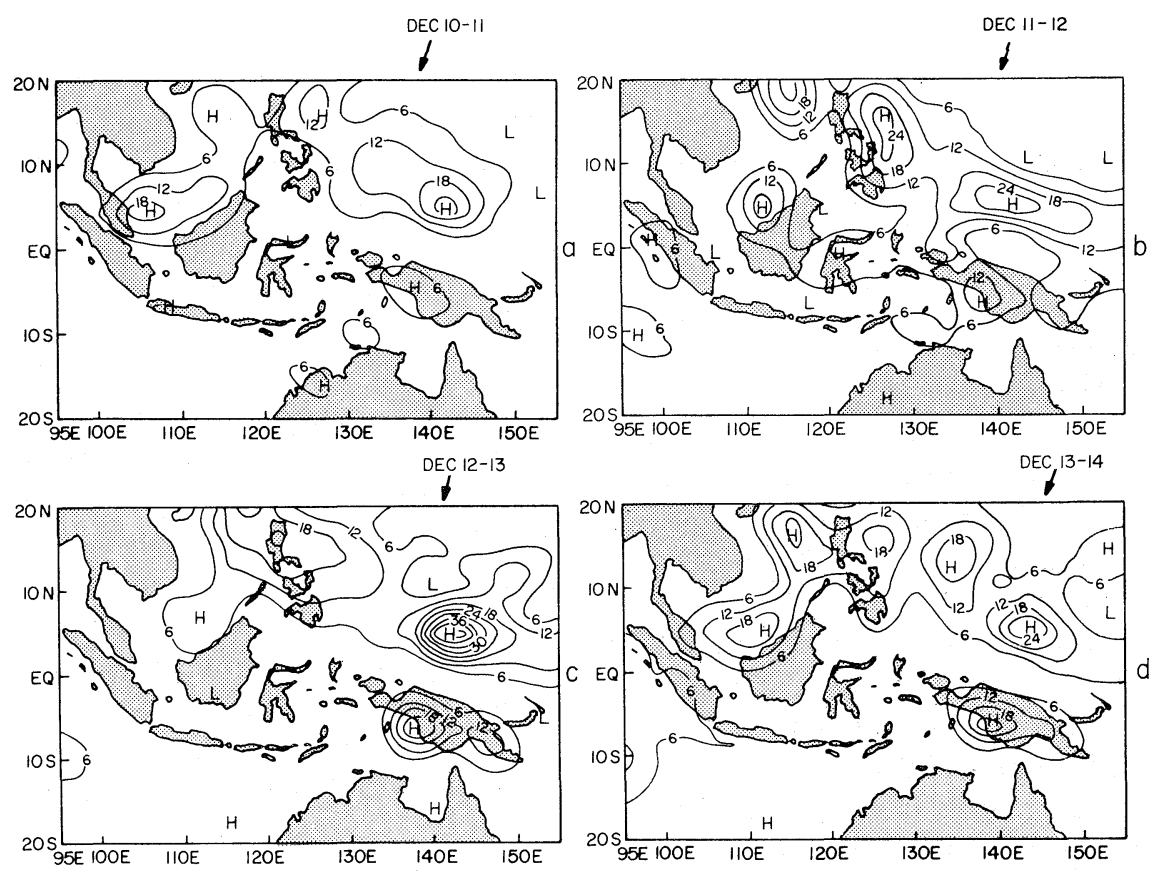

Fig. 13(a, b, c and d) 24 hourly rainfall rate in units $\mathrm{mm} \cdot \mathrm{day}^{-1}$ for the four respective periods.

a) December 10-11 1978

b) December 11-12 1978

c) December 12-13 1978

d) December 13-14 1978

resolution. The prediction of the $200 \mathrm{mb}$ flow was quite realistic to almost one week for the experiment with envelop orography, 11 vertical levels at a horizontal resolution of 42 waves. Fig. 12(a, b) illustrates a comparison of the observed and the predicted time averaged flow field at $200 \mathrm{mb}$ for the one week period, that was also shown in Krishnamurti et al. (1984). The close similarity between the observed and predicted positions of numerous trough ridge systems over the entire globe suggests that the stationary components are handled extremely well by the global model, especially during this period of the surge vortex.

Precipitation forecast during the four day period (Dec. 10 to Dec. 14, 1978) is illustrated in Fig. 13(a, b, c and d). 24 hourly totals of the predicted rainfall (units $\mathrm{mm} \cdot \mathrm{day}^{-1}$ ) for each day is illustrated here. The westward passage of the rainfall belt towards the South China Sea appears to be a reasonable prediction since that is consistent with the westward passage of cloud clusters as seen from satellite photographs. The westward passage of rainfall associated with the easterly wave is most conspicuous when we compare the rainfall amounts for December 1112 with December 13-14. During the first 24 hour period between December $11-12$ a rainfall maximum is located immediately to the west of Borneo. That center weakens somewhat in the ensuing 24 hours and intensifies again between December 13-14, 1978. By this time precipitation occupies most of South China Sea. A rainfall maximum on December 10-11 over most of the South China Sea appears to be related to the initial intensification of the cold surge well prior to the arrival of the easterly wave. The 24 hourly predicted rainfall, shown in Fig. 13 , illustrates the westward passage of the rainfall associated with the wave. Predicted rainfall amounts are of the order of $25 \mathrm{~mm} \cdot \mathrm{day}^{-1}$ averaged over Gaussian grid squares (roughly $2.2^{\circ}$ latitude by $2.2^{\circ}$ longitude). That is an underestimate if we compare it with the rainfall rates 


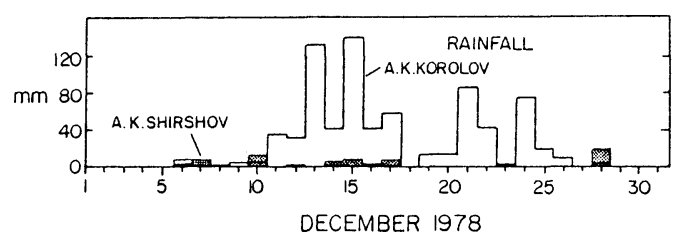

Fig. 14 Observed rainfall totals from Soviet ships Shirshov and Korolov during December 1978. This illustration was based on a study of Richard Johnson.

over the two Soviet ships that were stationed over the South China Sea during this period, Johnson and Priegnitz (1981). The location of these two ships were close to $110^{\circ} \mathrm{E}$ and $7^{\circ} \mathrm{N}$. The rainfall histories are shown in Fig. 14. As may be seen the rainfall amounts at these two neighboring ships is quite variable. It appears that we need to run these experiments with higher resolution models if we wish to forecast rainfall rates of the order of $150 \mathrm{~mm} \cdot$ day $^{-1}$

\section{Concluding Remarks}

Forecasting of day to day weather over the active winter monsoon region over and around the South China Sea is an extremely difficult problem. Most modelling exercises seem to show poor skill in predicting the winds or the precipitation fields. The westward propagating easterly waves and the surge vortices contribute significantly to the winter monsoon rainfall. These waves and the vortices modulate the rising branch of the local Hadley cell over this region. The present study is a first attempt on numerical weather prediction of the interaction of the cold surges from the Asian land mass and the westward propagating easterly waves near $5^{\circ} \mathrm{N}$. It is apparent from these studies that a clear distinction between the northerly flow along the Asian coast and the northeast trade wind system of the Pacific Ocean is only preserved if the vertical resolution in the planetary boundary layer is at least $100 \mathrm{mb}$. At a resolution of roughly $200 \mathrm{mb}$ these two wind systems merge and extend into the Indian Ocean. Forecasts over the winter monsoon region are somewhat improved when the horizontal resolution is increased to 42 waves triangular. Forecasts with 29 waves were not realistic over the winter monsoon region. The most marked improvement in the forecasts came from the inclusion of envelope orography. The region of South China Sea is flanked by a number of medium scale mountain ranges whose heights are on the order of $3 \mathrm{~km}$ each (see Fig. 8). The northerly continental monsoonal flow is confined to the South China Sea by these mountains. The easterly waves arriving into this region from north of Borneo undergo a strong interaction with the northerlies in this confined region. Thus steep, or envelope, orography seems to have a crucial role on the formation of the surge vortex. In this study we did not find any major impact from the inclusion of high resolution cloud winds from the Japanese satellite (GMS). That was due to the fact that most of the added winds did not enhance the description of the low level flows.

Further experimentation is necessary to improve upon the findings presented here.

\section{Acknowledgement}

The research reported here was supported by the NOAA Grant No. NA82AA-D-0004 and by the NSF Grant No. ATM 83-04809-02. The computations were carried out at the National Center for Atmospheric Research.

\section{References}

Chang, C.P., 1977: Viscous internal gravity waves and low frequency oscillations in the tropics. J. Atmos. Sci., 34, 901-910.

J.E. Erickson and K.U. Lau, 1979: Northeasterly cold surges and near equatorial disturbances over the Winter - MONEX area during December 1974. Mon. Wea. Rev., 107, 812-829.

Greenfiled, R.S. and T.N. Krishnamurti, 1979: The Winter Monsoon Experiments - Report of December 1978 Field Phase. Bulletin Amer. Met. Soc., 60, 5, 439-444.

Johnson, R.H. and Priegnitz, 1981: Convection over the southern South China Sea during December 1978, Part II: Effects on large-scale fileds. Mon. Wea. Rev., 109, 1615-1628.

Krishnamurti, T.N., R.J. Pasch, H. Pan, S. Chu and K. Ingles, 1983a: Details of low latitude medium range numerical weather prediction using a global spectral model I. Formation of a monsoon depression. $J$. Met. Soc. Japan, 61, 18-207.

S. Low-Nam and R. Pasch, 1983: Cumulus parameterization and rainfall rates II. Mon. Wea. Rev., 111, 815-828.

K. Ingles, S. Cocke, R. Pasch and T. Kitade, 1984: Details of low latitude medium range nu- 
merical weather prediction using a global spectral model II. (To be published in J. Met. Soc. Japan).

Lim, H. and C.P. Chang, 1981: A theory for midlatitude forcing of tropical motion during winter monsoons. J. Atmos. Sci., 38, 2377-2392.

Tiedtke, M., 1983: The sensitivity of the time-mean large-scale flow to cumulus convection in the
ECMWF model. Workshop on Convection in largescale numerical models, ECMWF, 297-316.

Wallace, J.M., S. Tibaldi and A.J. Simmons, 1983: Reduction of systematic forecast errors in the ECMWF model through the introduction of envelope orography. Quart. J. Roy. Met. Soc., 109, 683-718.

\title{
冬期モンスーン中のサージ低気圧の数值予報
}

\section{Ming-Cher Tsai and T.N.Krishnamurti}

\author{
(米国フロリダ州立大学)
}

冬季モンスーン中に南シ十海で形成されるサージ低気圧渦を研究するために，数例の数值実験を行な つた。その実験では, モデルに用いる水平および鉛直方向の分解能, 雲観測による風デー夕導入の分解 能そしてまた地形の形状などによる予報性が調べられた。その結果，そのサージ低気圧渦は，分解能の 高いモデル（波数42, 鉛直11層, エンヴェロプ地形）においてのみ再現可能であった。一方，雲観測風 の分解能の影響はほとんど無かった。総観的解析では, 西進する偏東風波動と東シ十海上の準定常寒気 吹出しとの相互作用が調べられたが, 低気圧発生に対するその役割が数值実験のみならず観測的にも認 められた。それはまた急な地形の導入に敏感であるらしい。 